\title{
Bronchial provocation tests using methacholine, cycle ergometer exercise and free running in children with intermittent asthma
}

\author{
Ana C. T. G. Souza, ${ }^{1}$ Carlos A. C. Pereira ${ }^{2}$
}

\begin{abstract}
Objective: To compare airway responsiveness to methacholine, cycle ergometer exercise and free running in children with intermittent asthma.

Methods: A randomized study was conducted with 30 children of both genders with intermittent asthma. Each child was submitted to challenge testing on three separate days, in random order: a) Methacholine challenge using a dosimeter; b) Exercise challenge testing - free running along a 50-meter-long corridor; c) Dry-air exercise challenge on a cycle ergometer. Target heart rate during exercise was 80 to $90 \%$ of the maximum predicted value. Spirometry was performed 3, 6,10,15,20 and 30 minutes after exercise. Exercise-induced bronchospasm was defined as a decrease in $\mathrm{FEV}_{1}$ of $\geq 10 \%$ in comparison to pretest values.

Results: Mean age was $11 \pm 3$ years. $\mathrm{FEV}_{1}$ and $\mathrm{FEV}_{1} / \mathrm{FVC}$ ratios were normal and similar before all provocation tests. The maximum heart rate was $178 \pm 7 \mathrm{bpm}$ during cycling and $181 \pm 6 \mathrm{bpm}$ during the free running test $(p>0.05)$. Significant bronchospasm was observed with methacholine in 23 cases, after free running in 19 and after

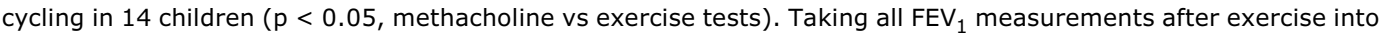
account, the free running test resulted in greater exercise-induced bronchospasm in comparison with exercise made on a cycle ergometer $\left(p=0.003, \chi^{2}=8.948\right)$. There was a significant, but poor, correlation between the maximum percentage decrease in $\mathrm{FEV}_{1}$ after free running and cycling $(r=0.46, p<0.01)$.

Conclusions: Methacholine challenge identifies a greater number of asthmatics in comparison to exercise tests. When bronchial provocation test with methacholine is not available, free running should be the test of choice due to its simplicity and greater ability to induce bronchospasm.
\end{abstract}

J Pediatr (Rio J). 2005;81(1):65-72: Asthma, bronchial provocation tests, methacholine chloride, exercise test, exercise-induced asthma.

\section{Introduction}

Asthma is a multifactorial disease determined by the interaction of genetic and environmental factors, which result in chronic airway inflammation.

1. Preceptor of Pediatric Pulmonology, Hospital do Servidor Público Estadual Francisco Morato de Oliveira (HSPE-FMO), São Paulo, SP, Brazil.

2. Ph.D., School of Medicine, Universidade Federal de São Paulo (UNIFESP. EPM). Director of the Laboratory of Lung Functioning, Hospital do Servidor Público Estadual Francisco Morato de Oliveira (HSPE-FMO), São Paulo, SP, Brazil.

Manuscript received Mar 23 2004, accepted for publication Oct 272004.

Suggested citation: Souza AC, Pereira CA. Bronchial provocation tests using methacholine, cycle ergometer exercise and free running in children with intermittent asthma. J Pediatr (Rio J). 2005;81:65-72.
There is no "gold standard" for the diagnosis of asthma ${ }^{1}$, and the disease often is diagnosed by the combination of detailed clinical history, presence of totally or partially reversible bronchial obstruction after the use of a bronchodilator and diurnal variation of airway obstruction. However, the symptoms of asthma are nonspecific and may occur in isolation. This is especially observed in children, in whom recurrent coughing, mainly during the night or after exercise, may be the only clinical manifestation of asthma. The objective measures of bronchial hyperresponsiveness are used in cases of diagnostic suspicion, when there are respiratory symptoms that may indicate asthma, in case of normal spirometric findings. 
The correlation between asthma and bronchial responsiveness is complex and controversial, though, ${ }^{2,3}$ since several studies have shown that normal individuals who have positive bronchial provocation test results with bronchoconstrictive and asthmatic agents may be nonresponsive sometimes. ${ }^{4}$

Bronchial provocation challenge by exercise has been proposed for the diagnosis of asthma. ${ }^{5}$ This test is usually more specific and can distinguish asthma from other chronic lung diseases, 6,7 but it is less sensitive than bronchial provocation with methacholine or histamine in diagnosing asthma. Some authors also observed that bronchial provocation challenge by exercise and methacholine or histamine does not always identify the same individuals. ${ }^{1,8}$

Different exercise modalities seem to result in different degrees of bronchospasm. Some studies found the following decreasing order in exercise-induced bronchospasm (EIB), when a similar exercise load was used: free running $>$ treadmill running $>$ cycle ergometer $>$ swimming. ${ }^{5}$ Other authors noted that when the exercise is performed in an environment where humidity and temperature are controlled, it is the attained ventilation that determines the degree of bronchospasm, regardless of the exercise type. ${ }^{9}$ Therefore, there seems to be no consensus about this aspect of EIB.

The aim of the present study was to compare two exercise challenge tests, by using different methodologies (dry-air exercise challenge on a cycle ergometer and free running in room air), with the bronchial provocation test with methacholine in the diagnosis of asthma in children with intermittent asthma. The hypothesis was that a standardized exercise challenge test could be an alternative to the bronchial provocation test with methacholine, when the latter is not available. The two exercise tests were also compared to verify whether there is some difference between them concerning the diagnosis of asthma and the respective correlation with bronchial provocation with methacholine.

\section{Patients and methods}

Forty-three children ( 6 to 15 years old) diagnosed with intermittent asthma, treated at the outpatient clinic of pediatric pulmonology of Hospital do Servidor Público Estadual Francisco Morato de Oliveira, were selected. Thirteen patients did not complete the study for different reasons: they could not accomplish all the tests, they had respiratory infection, they missed their follow-up appointments because they changed address (moved to another state), climatic conditions were inappropriate, or they did not show up on the scheduled day for the second exercise test.

The sample size was calculated by binomial proportion, considering an $80 \%$ positivity rate for bronchial provocation with methacholine $\mathrm{10}^{11}$ and a $60 \%$ positivity rate for the EIB test $^{12}$ in patients with intermittent asthma, with $\alpha=0.05$ and $B=0.20 .13$

The diagnosis of asthma was established according to clinical criteria including a history of at least two episodes of dyspnea and/or wheezing relieved with the use of bronchodilators (after other diagnoses were ruled out).
Asthma was classified as intermittent according to the Global Initiative for Asthma (NIH) ${ }^{14}$ after following up patients for at least three months at the outpatient clinic of pediatric pulmonology. None of the patients was receiving oral or inhaled corticosteroid, disodium cromoglycate, nedocromil, theophylline, antileukotrienes and long-acting beta-2 agonists. No children had presented with clinically apparent upper airway infection or exacerbation of asthma in the last six weeks prior to the study.

All patients were asked not to drink coffee, tea or soft drinks containing caffeine two hours before the test, to discontinue the use of short-acting bronchodilators 12 hours before and also to discontinue the use of short- and long-acting antihistamines 48 hours and five days before the tests, respectively.

The study was carried out at the Pulmonary Function Laboratory of Hospital do Servidor Público Estadual. The tests were always performed in the morning (8-10 a.m.), at an average temperature of 21 and $22^{\circ} \mathrm{C}$ and relative humidity around $50 \%$ in order to standardize the factors that influence EIB.

At baseline spirometry, all patients had forced vital capacity (FVC) and forced expiratory volume in 1 second $\left(\mathrm{FEV}_{1}\right)$ greater than or equal to $80 \%$ and $\mathrm{FEV}_{1} / \mathrm{FVC}$ greater than $75 \%$ of the predicted value, and were then submitted to the bronchial provocation test with methacholine. The order of the tests (cycle ergometer exercise and free running) was randomly chosen on the computer. There was a minimum interval of 24 hours and a maximum interval of 10 days between each of the three tests.

All parents or surrogates signed an informed consent form allowing their children to participate in the study. The study protocol was approved by the local Ethics and Research Committee.

\section{Spirometry}

Spirometry was performed by a laboratory technician, certified by the SBPT (Brazilian Society of Pulmonology and Thisiology), using an Anamed spirometer, model AM4000 (Brazil), according to the ATS (American Thoracic Society). ${ }^{15}$ The predicted $\mathrm{FEV}_{1}$ values were based on the data described by Polgar $\&$ Promadhat. ${ }^{16}$ Noseclips were used.

\section{Bronchial provocation with methacholine}

Bronchial responsiveness with methacholine chloride was measured using a dosimeter (Multispiro, Incorporated Multichalenge Nebulizer System, USA), coupled to a PulmoAid compressor, DeVilbiss Co. (Somerset, PA, USA). Two milliliters of the solution (concentrations of $0.25 ; 1.25 ; 2.5$; 5; 10 and $25 \mathrm{mg} / \mathrm{ml}$ ) was added to the nebulizer and an aerosol was produced by the compressor at a flow rate and pressure of $20 \mathrm{psi}$, appropriate for an output of $0.045 \mathrm{ml} /$ discharge (total of $0.225 \mathrm{ml}$ with five discharges). The output was regulated by a solenoid valve that was activated during inspiration and remained open for 0.6 seconds. The patients wore noseclips and were told to take five deep breaths going from functional residual capacity 
(FRC) to total lung capacity (TLC) and then to hold their breath for 2 to 5 seconds at TLC in order to maximize pulmonary deposition. This was repeated five times in a row for each methacholine concentration. The doses were administered at five-minute intervals and $\mathrm{FEV}_{1}$ was measured one minute after the last inhalation.

The test result was expressed by the cumulative dose that caused a $20 \%$ decrease in $\mathrm{FEV}_{1}\left(\mathrm{PD}_{20} \mathrm{FEV}_{1} \%\right)$ obtained by linear interpolation around the desired cutoff point of the fall in $\mathrm{FEV}_{1}$ values. The cutoff dose was $6.6 \mu \mathrm{mol}, 17$ considering that:

- Increased responsiveness: less than or equal to $0.125 \mu \mathrm{mol}$;

- moderate responsiveness: between 0.125 and $1.99 \mu \mathrm{mol}$;

- mild responsiveness: between 2.00 and $6.6 \mu \mathrm{mol}$.

\section{Free running}

After having their baseline lung function measured, the children ran along a 50-meter corridor, breathing in the ambient air. The children were encouraged to run for 1 to 2 minutes until they reached the target submaximal heart rate (HR), around 80 to $90 \%$ of the maximum HR (220age). From this point, HR was maintained for six minutes. HR was controlled by a pulse oximeter (Dixtal), and recorded every minute. The criteria for plethysmographic wave evaluation were met on all tests. Noseclips were used to induce mouth breathing during the tests.

\section{Cycle ergometer exercise}

The children exercised on a cycle ergometer (Godart, Netherlands). The workload was adjusted in order to reach a heart rate between 80 and $90 \%$ of the maximum HR after a warm-up period of 1 to 2 minutes, using the following equation: workload $=\left(53.76 \times\right.$ measured $\left.\mathrm{FEV}_{1}\right)-11.07$.

The workload was adjusted to $60 \%$ in the first minute, $75 \%$ in the second minute and 90 to $100 \%$ for the remaining time (6 minutes). HR was monitored every minute to determine whether submaximal HR was being reached. During this test, the children inhaled dry air through a mouthpiece coupled to a Hans Rudolph one-way valve. The dry air was produced by a compressed air cylinder and collected in a Douglas bag. HR was also measured throughout the exercise using a pulse oximeter (Dixtal). The temperature of the dry air leaving the Douglas bag was measured throughout the test. Noseclips were also used for the test.

After each exercise test, spirometry was performed again at $3,6,10,15,20,30$ minutes after the exercise by a laboratory technician, certified by the SBPT. The highest value of the three $\mathrm{FEV}_{1}$ measurements was considered to represent each interval. The intensity of the maximum response was assessed by the largest decrease in $\mathrm{FEV}_{1}$ after the exercise, expressed as percentage of the baseline $\mathrm{FEV}_{1}$. A decrease in $\mathrm{FEV}_{1}$ of at least $10 \%$ after the exercise (decrease in baseline $\mathrm{FEV}_{1} / \mathrm{FEV}_{1} \times 100$ ) was considered as a positive response, since this value represents twice the coefficient of variation for the $\mathrm{FEV}_{1}$ measurement. FEV 1 was used to assess the response to exercise because it has less intrasubject variability than the peak expiratory flow (PEF).

After the tests, those patients with an FEV $_{1}$ less than $90 \%$ of the baseline value received a bronchodilator (salbutamol spray, $200 \mathrm{mcg}$ ). The patients were only allowed to leave if their $\mathrm{FEV}_{1}$ was greater than $90 \%$ of the baseline value, after one or more applications of salbutamol.

\section{Statistical analysis}

All statistical tests were made using SPSS version 11 (www.spss.com). General data were expressed as mean \pm standard deviation. The comparison of continuous data between the three groups was made by repeated measures or paired t test ANOVA. The analysis of specific differences between the different time periods was made using Tukey's test. The correlation between the variables for continuous and non-continuous distribution data was made using Pearson's correlation coefficient and Spearman's rank correlation test, respectively. The concordance between the qualitative results of the tests was established by using the McNemar test, and the association between variables was made by the chi-square test $\left(\chi^{2}\right)$.

An alpha value of 0.05 was established for the rejection of the null hypothesis.

\section{Results}

The three bronchial provocation tests (methacholine, cycle ergometer and free running) were well accepted and easily performed by the children. All of the children reached the target heart rate proposed by the exercise tests.

Three $(10 \%)$ children were asymptomatic in the last year and showed a negative result on the bronchial provocation test with methacholine ("asthma in remission"). However, they had a mild wheezing episode after 45 days, 3 and 4 months after the study, and were therefore included in the analysis.

The patients' general characteristics and the mean baseline $\mathrm{FEV}_{1}$ (absolute and $\%$ of the predicted value), FVC (absolute and \% of the predicted value) and $\mathrm{FEV}_{1} / \mathrm{FVC}$ are shown in Table 1 . Sex distribution was similar and the spirometric results were as predicted.

Pulmonary function baseline values before the three bronchial provocation tests were similar on each of the days $\left(\mathrm{FEV}_{1}, \%\right.$ of the predicted value, methacholine $=101 \pm 12$, free running $=102 \pm 12$ and cycle ergometer $=102 \pm 12$, FVC $\%$ of the predicted value, methacholine $=102 \pm 11$, free running $=101 \pm 12$ and cycle ergometer $=102 \pm 10$ and $\mathrm{FEV}_{1} /$ FVC methacholine $=86 \pm 5$, free running $=88 \pm 5$ and cycle ergometer $=87 \pm 4$, analysis of variance - ANOVA, FEV 1 $F=0.173, p=0.841$ and $F V C F=0,008$ and $p=0,99)$. Temperature and heart rate values were similar on the two days of exercise tests (cycle ergometer $=21 \pm 1{ }^{\circ} \mathrm{C}$ and free running $=22 \pm 2{ }^{\circ} \mathrm{C}$; init ial heart rate, cycle ergometer $=87 \pm 10 \mathrm{bpm}$ and free running $=86 \pm 11 \mathrm{bpm}$; target heart rate, cycle ergometer $=178 \pm 7 \mathrm{bpm}$ and free running $=181 \pm 6 \mathrm{bpm}$, paired $t$ test $=\mathrm{NS}$ ). 
Table 1 - Patients' general characteristics

\begin{tabular}{lc}
\hline Variables & Meantstandard deviation \\
\hline Age $($ years $)$ & $11 \pm 3$ \\
Sex $(\mathrm{M} / \mathrm{F})$ & $14 / 16$ \\
$\mathrm{FEV}_{1}(\mathrm{I})$ & $2.39 \pm 0.70$ \\
$\mathrm{FEV}_{1}(\%$ of the predicted value) & $98 \pm 12$ \\
FVC $(\mathrm{I})$ & $2.76 \pm 0.80$ \\
FVC $(\%$ of the predicted value) & $102 \pm 11$ \\
FEV $_{1} / \mathrm{FVC}(\%)$ & $86 \pm 5$
\end{tabular}

$\mathrm{M}=$ male; $\mathrm{F}$ = female; $F E V_{1}=$ forced expiratory volume in 1 second; $\mathrm{FVC}=$ forced vital capacity

The frequency of positive results on each test was as follows: methacholine $\leq 6.6 \mathrm{mmol}$ in $23(77 \%, 95 \% \mathrm{CI}$ between 62 and 92\%), decrease in $\mathrm{FEV}_{1} \geq 10 \%$ in free running and on the cycle ergometer in 19 (63\%, 95\%CI $45-$ $81 \%)$ and 14 children (47\%, 95\%CI between $29-58 \%$ ), respectively.

Figure 1 shows the changes in $\mathrm{FEV}_{1}$ values (\% of the baseline value) after the cycle ergometer exercise and free running, respectively, according to the duration of exercise. The greater decreases occurred on the free running test ( $p=0.003, \chi^{2}=8.948$, Friedman's test). For most children, the highest average decrease in $\mathrm{FEV}_{1}$ (\% of the baseline value) after bronchial provocation with cycle ergometer exercise occurred at 6 minutes (statistically significant in relation to the baseline value, $p=0.007$, analysis of variance followed by Tukey's test) and after free running at 3 minutes (statistically significant in relation to the baseline value, $p=0.001$, analysis of variance followed by Tukey's test).

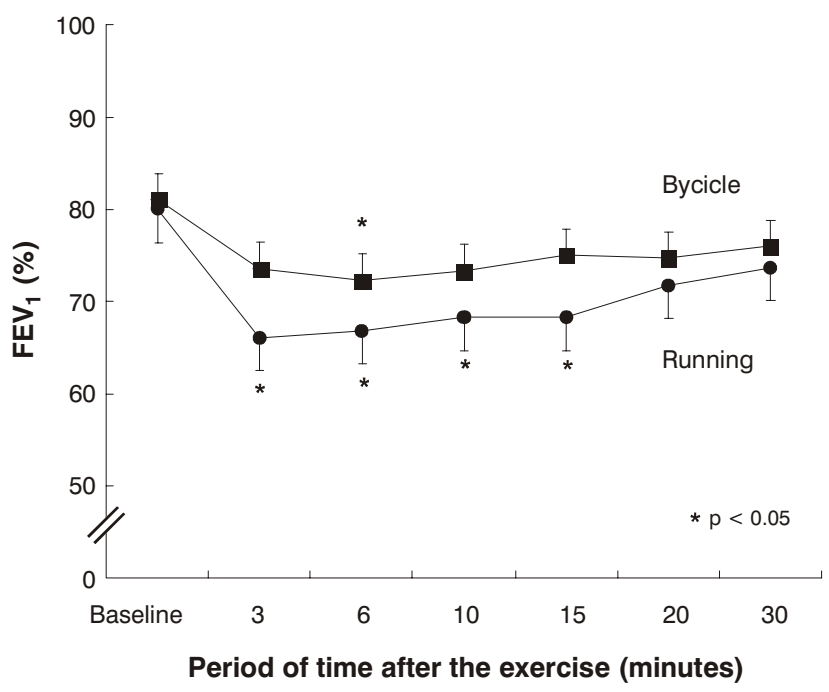

Figure 1 - $F E V_{1}$ values (\% of the predicted value) after the cycle ergometer exercise and free running in children with exercise-induced bronchospasm. Values are the means \pm standard deviation
With regard to $\mathrm{PD}_{20}$ for methacholine, the patients responded as follows: two (7\%) showed increased hyperresponsiveness, 16 (53\%) had moderate hyperresponsiveness, five $(17 \%)$ demonstrated mild hyperresponsiveness and seven $(23 \%)$ showed no response. The median $\mathrm{PD}_{20}$ for methacholine was $1.28 \mu \mathrm{mol}$. The largest decreases in $\mathrm{FEV}_{1}$ on the ergometer and on the free running test were 52 and $53 \%$, respectively. The highest average decrease in $\mathrm{FEV}_{1}$ (in \% of the baseline value) was 13.6 for the ergometer exercise and $18.5 \%$ for free running $(p=0.01)$.

Figure 2 shows a significant but poor correlation between the percentage values of maximum decrease in $\mathrm{FEV}_{1}$ on the ergometer and in free running $(r=0.46, p<0.01,95 \% \mathrm{CI}$ $0.11-0.66)$. Concordance was noted in only 13 cases, and the two tests yielded positive results in six and negative results in seven individuals.

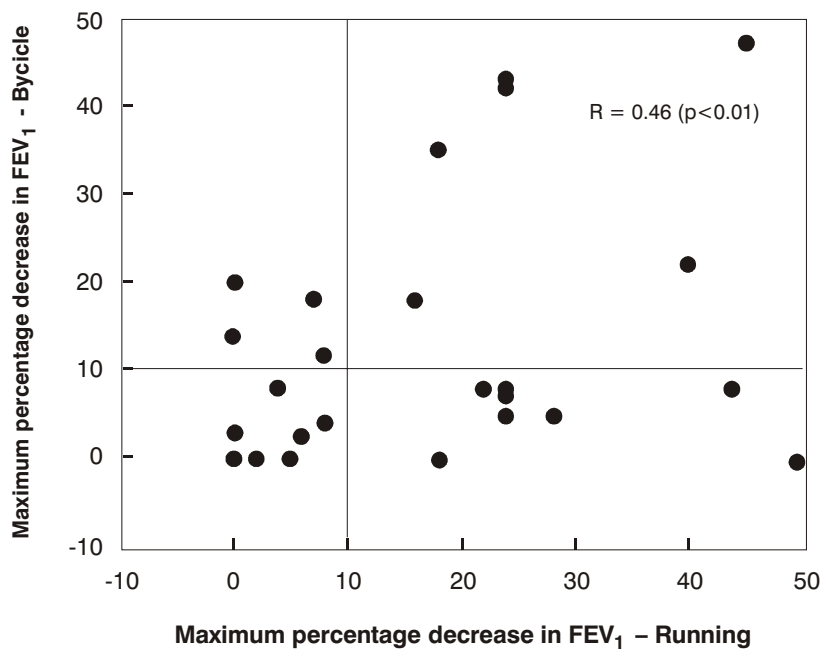

Figure 2 - Correlation between the percentage values of maximum decrease in $\mathrm{FEV}_{1}$ on the ergometer and in free running

By analyzing the concordance between the decrease in $\mathrm{FEV}_{1}$ greater than or equal to $10 \%$ in the ergometer exercise and the positive or negative response to the methacholine challenge test, it was observed that 18 tests were concordant and that 12 were discordant, and among the 12 discordant tests, 11 were positive only for methacholine $(p=0.006$, McNemar test). By performing the same analysis on the free running test, it was observed that 24 tests were concordant with methacholine and that six were discordant. Of the discordant tests, all were positive only for methacholine ( $p=0.002$, McNemar test).

There was no significant correlation between the percentage of maximum $\mathrm{FEV}_{1}$ decrease on the ergometer and the $\mathrm{PD}_{20}$ for methacholine ( $r$ o $=0.311, \mathrm{p}=0.094$ ) nor between the maximum decrease in free running and the $\mathrm{PD}_{20}$ for methacholine ( $r$ o $=0.086, \mathrm{p}=0.652$ ). 
Figure 3 shows the response to exercise of all study participants, according to the time of $\mathrm{FEV}_{1}$ decrease and the type of exercise. Free running showed a larger number of patients with a positive response to the exercise test $\left(\mathrm{FEV}_{1}\right.$ decrease $>10 \%$ ) and also with an $\mathrm{FEV}_{1}$ greater than $40 \%$.

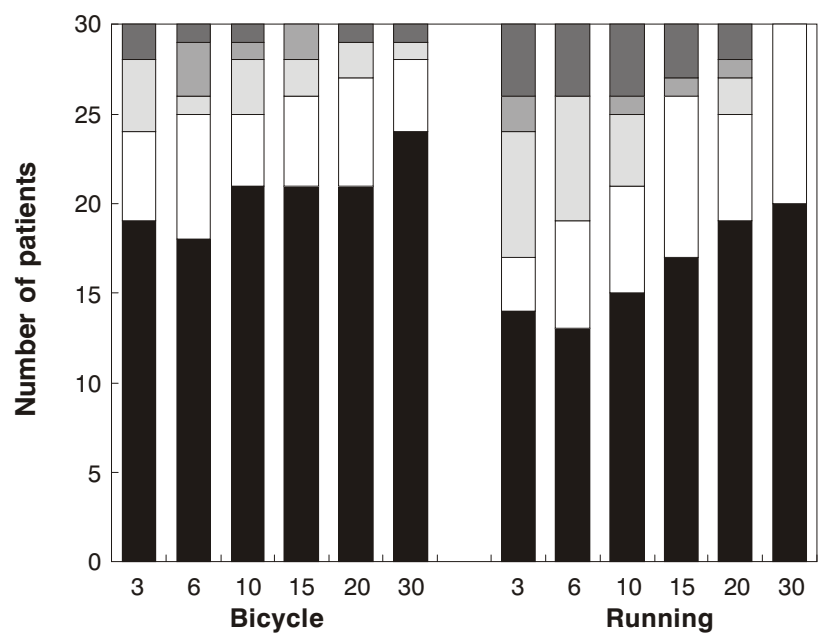

Period of time after the exercise (minutes)

0-10 $\square 11-20 \quad \square 21-30 \quad \square 31-40 \quad \square>41$

Figure 3 - Number of patients with FEV 1 decrease up to $10 \%$, from 11 to $20 \%$, from 21 to $30 \%$, from 31 to $40 \%$ and greater than $40 \%$ according to the period of time after the exercise and the type of exercise

\section{Discussion}

In this study, we compared two types of exercises (cycle ergometer and free running) with bronchial provocation with methacholine, using exercise as an alternative to the pharmacological challenge test for the diagnosis of asthma. There was a positivity of $77 \%$ for methacholine, $63 \%$ for free running and $47 \%$ for the cycle ergometer.

Dry air was used in the ergometer exercise in order to optimize the bronchoconstrictive response, whereas only noseclips were used for the free running test to force mouth breathing, and even so, the highest positivity was that obtained from the free running test. We did not use an airconditioned laboratory for rigid temperature and humidity control, but both tests were performed within a maximum period of 10 days in order to avoid great climatic changes, and whenever this was the case, the tests were rescheduled (with a maximum of 10 days between the tests). Due to these criteria, three patients were excluded from the study. Relative humidity has more influence than temperature on the production of EIB, 18 and for this reason, the tests were not performed during the summertime. Air humidity greater than $50 \%$ would not be enough to produce bronchospasm in susceptible individuals.
Only heart rate was used to measure the intensity of the exercise. During exercise, cardiac output increases in proportion to oxygen consumption. Cardiac output at a given submaximal oxygen consumption ( 80 to $90 \%$ of maximum $H R$ ) is similar in free running and on the cycle ergometer. ${ }^{19}$ Nevertheless, the use of heart rate to determine the intensity of exercises is somewhat more variable than the direct measurement of oxygen consumption. ${ }^{19}$ Perhaps, if oxygen consumption and ventilation were directly measured, the difference between the tests could be better understood.

\section{Bronchial hyperresponsiveness (BHR)}

BHR is often measured by the bronchial provocation test with histamine or methacholine; however, bronchial response to exercise can also be used. The use of exercise as objective measure of bronchial hyperresponsiveness in asthma is quite interesting since it is a physiological stimulus, easy to use and widely accepted by children, as observed in this study.

Epidemiological studies show BHR in only 40 to $60 \%$ of asthmatic patients. This is partly due to the absence of recent symptoms when the test was performed, but also to other factors such as: bronchial responsiveness has a unimodal distribution in the population (overlapping of healthy and asthmatic individuals), and the distinction between asthmatic and healthy subjects is arbitrary; individual variability of bronchial responsiveness over time; change in airway responsiveness with age, which is larger in children, especially among atopic ones. ${ }^{1,2,4} \mathrm{BHR}$ also is found among smokers, former asthmatics, nonasthmatic patients with allergic rhinitis and even in atopic individuals without any clinical manifestations associated. ${ }^{10}$ Therefore, depending on clinical and epidemiological circumstances, the presence of BHR is not synonymous with asthma, nor does its absence rule out this diagnosis.

Clinical trials demonstrate that patients with intermittent asthma have BHR around $80 \% .{ }^{10,11}$ In the epidemiological case, if the pretest probability is low (a $5 \%$ asthma prevalence), the post-test probability is also low. At the pulmonary function laboratory, where the pretest probability is $40 \%$ or more, the post-test probability exceeds $80 \%$. When analyzing a diagnostic test, one should not consider only sensitivity and specificity. The prevalence of the disease is also essential to assess the results. ${ }^{10}$

The present study revealed that $77 \%$ of the children with intermittent asthma responded to the bronchial provocation test with methacholine. Although this value is slightly lower than those observed in previous studies about intermittent asthma, one should not forget that, in this study, three patients were asymptomatic in the last 12 months, which might have contributed to a lower percentage of positive tests. Moreover, patients with intermittent asthma may have bronchodilation when submitted to bronchial provocation tests because deep inspiration may eliminate bronchospasm, resulting in false-negative tests. ${ }^{20}$ These cases were included so that 
the relative sensitivity of different tests could be compared in a group of children with intermittent asthma and with recent remission.

\section{Exercise}

Bronchial provocation challenge by exercise is indicated for individuals with history of activity limitations due to bronchospasm, and is used to assess the response to EIBspecific medications and also to diagnose asthma. ${ }^{5}$ According to several studies, 40 to $90 \%$ of asthmatic patients respond abnormally to exercise, $1,2,9,21,22$ and just as occurs with bronchial provocation with methacholine or histamine, the sensitivity of the test is higher in nonepidemiological studies.

However, the specificity (healthy individuals with negative result/total of healthy individuals) of exercise tests is high (around 90\%).17,22 In epidemiological studies, the predictive value of the exercise test (the probability of an individual with a positive result to have asthma) is low, ${ }^{2}$ since some nonasthmatics respond to exercise and in the general population there are far more nonasthmatics than asthmatics. This large variability between clinical and population-based studies is also due to the selection of patients, different protocols for exercise tests, definition of what is considered normal and an asthmatic patient, and different response criteria. ${ }^{9,17}$

Several cutoff points have been proposed regarding the percentage decrease in $\mathrm{FEV}_{1}$ on the exercise test 17,22 in order to characterize a test as positive; however, the choice is arbitrary, as the distribution of the decrease is unimodal. In the present study, values of $10 \%$ or more for $\mathrm{FEV}_{1}$ decrease were significant, since patients with a previously established diagnosis were included. Less stringent positivity criteria should be chosen when the pretest probability of the disease is high; when such probability is low, more stringent criteria should be used, thus minimizing the proportion of false-positive results. ${ }^{17}$ The benefit/risk ratio of the treatment should also be considered: relatively less stringent criteria are used when the expected benefits of the treatment are substantial; stringent criteria should be applied when this ratio is low. ${ }^{10}$

Therefore, whereas the exercise test has a relatively poor role in population-based studies in assessing the incidence of asthma, it is quite useful in clinical trials and in distinguishing asthma from other chronic lung diseases, including those with bronchial hyperresponsiveness to methacholine. ${ }^{6,7}$

In the present study, the positivity of the ergometer exercise was slightly lower than that described in patients with intermittent asthma, which corresponds to approximately $60 \%{ }^{12}$ However, it should be underscored that not all patients were responsive to bronchoconstriction with methacholine, which reduces the response to the test.

\section{Exercise versus methacholine}

In the available literature, no consensus exists about the correlation of the intensity of bronchospasm observed after bronchial provocation with drugs and exercise. 12,22,23 The intensity of exercise-induced bronchoconstriction did not show a significant correlation with bronchial provocation after the inhalation of methacholine (ergometer: rho $=0.311, p=0.094$ and free running: rho $=0.086, \mathrm{p}=0.652$ ).

In some patients, there was some discrepancy between the methacholine challenge and free running tests and between the methacholine and cycle ergometer tests, thus corroborating the results of clinical trials in which bronchial provocation tests with histamine or methacholine and exercise probably measure different aspects of bronchial hyperresponsiveness. ${ }^{1,22}$ By comparing the bronchial provocation tests, methacholine was statistically better than both exercise tests because it detected the largest number of patients with asthma (methacholine versus ergometer: $p=0.006$; methacholine versus free running: $\mathrm{p}=0.002$ ). We also observed that children with $\mathrm{PD}_{20}$ greater than $3.74 \mu \mathrm{mol}$ did not show a decrease in $\mathrm{FEV}_{1}$ after the exercise greater than $20 \%$. The superiority of bronchial provocation tests with methacholine or histamine compared to exercise tests in the diagnosis of asthma also was observed by other authors. ${ }^{2}$

\section{Free running versus cycle ergometer exercise}

Under carefully controlled and standardized conditions, free running produced more EIB than did the exercise on the cycle ergometer ( $63 \%$ in free running and $47 \%$ on the cycle ergometer); furthermore, there were significantly larger $\mathrm{FEV}_{1}$ decreases in free running compared to the exercise on the cycle ergometer, even when cold air inhalation was used for the ergometer test, between 3 and 15 minutes of exercise. Also, at all times, free running had the largest number of individuals with an $\mathrm{FEV}_{1}$ decrease greater than or equal to $10 \%$. In addition, severe EIB ( $>40 \%$ ) also was found more often in the free running exercise.

Several factors influence the development and intensity of EIB, such as: type of physical activity, environmental conditions, intensity and duration of the exercise (oxygen consumption and ventilation). 5,9,18 According to Otani et al., the intensity of the response to the exercise is directly related to airway vascular hyperpermeability, eosinophilic inflammation and bronchial hyperreactivity. ${ }^{24}$

In an old but classic review of the literature ${ }^{5}$ on exercise-induced asthma, the authors demonstrated that free running had a more asthmogenic effect, disregarding environmental factors such as relative humidity and temperature. Other studies with similar workloads (direct measurement of oxygen consumption) showed contradictory results. 25,26

It is likely, however, that the type of exercise itself may have an independent effect on the bronchoconstrictive response to exercise. Bar-Yishay et al. ${ }^{27}$ compared children who practiced free running and swimming with inhalation of dry air under the same ventilation and oxygen consumption conditions and noted that free running produced EIB more frequently. 
Other environmental factors (e.g.: exposure to pollutants) should also be taken into account. The practice of exercise in environments with high concentrations of ozone associated with the use of noseclips (mouth breathing) reduces the removal of this gas from the inspired air, leading to a substantially higher intrathoracic deposition and potentially producing remarkable bronchospasm in the free running test. 28

With regard to ventilation, the studies yielded inconsistent results. Some authors observed higher ventilation in the cycle ergometer exercise, ${ }^{29-31}$ whereas others ${ }^{32}$ found variable results depending on the analyzed individuals, controls or athletes. However, in these two groups, during maximum exercise, ventilation was significantly higher in the treadmill exercise. Gavin \& Stager ${ }^{33}$ showed that ventilation may probably vary according to the type of exercise, but differences in oxygen saturation between the cycle ergometer exercise and free running cannot be explained by the changes in ventilation parameters.

West et al. ${ }^{21}$ in their epidemiological study, concluded that the use of a cycle ergometer with dry air inhalation is a sophisticated method that offers little advantage over free running. These authors suggest the standardization of minute ventilation in future studies.

The pathophysiological mechanisms involved in the discrepancy between the two exercise tests have not been properly clarified yet. New studies should be performed comparing the different types of exercises with ventilatory measurements in a larger number of cases.

We conclude that bronchial provocation with methacholine detects a larger number of asthmatic individuals than the two exercise tests, and is therefore the method of choice for the diagnosis of asthma. When bronchial provocation with methacholine or similar drug is not available, a standardized exercise test may be an alternative, since $82 \%$ of the patients with a positive result on the methacholine test showed a significant decrease on the free running test. For the study of exercise-induced asthma, the free running test, a simple and practical method, is better than the cycle ergometer exercise, as it identifies a larger number of asthmatic individuals and produces significantly larger decreases in $\mathrm{FEV}_{1}$.

\section{References}

1. Siersted HC, Mostgaard G, Hyldebrandt N, Hansen HS, Boldsen $\mathrm{J}$, Oxhoj H. Interrelationships between diagnosed asthma, asthma-like symptoms, and abnormal airway behaviour in adolescence: the Odense Schoolchild Study. Thorax. 1996;51:503-9.

2. Backer V, Ulrik CS. Bronchial responsiveness to exercise in a random sample of 494 children and adolescents from Copenhagen. Clin Exp Allergy. 1992;22:741-7.

3. Pattemore PK, Asher MI, Harrison AC, Mitchell EA, Rea $\mathrm{HH}$, Stewart AW. The interrelationship among bronchial hyperresponsiveness, the diagnosis of asthma, and asthma symptoms. Am Rev Respir Dis. 1990;142:549-54.

4. Salome CM, Peat JK, Britton WJ, Woolcock AJ. Bronchial hyperresponsiveness in two populations of Australian schoolchildren. I. Relation to respiratory symptoms and diagnosed asthma. Clin Allergy. 1987;17:271-81.
5. Anderson SD, Silverman M, Konig P, Godfrey S. Exerciseinduced asthma. Br J Dis Chest. 1975;69:1-39.

6. Carlsen K-H, Engh G, Mork M, Schroder E. Cold air inhalation and exercise-induced bronchoconstriction in relationship to metacholine bronchial responsiveness: different patterns in asthmatic children and children with other chronic lung diseases. Respir Med. 1998;92:308-15.

7. Godfrey S, Springer C, Noviski N, Maayan C, Avital A. Exercise but not methacholine differentiates asthma from chronic lung disease in children. Thorax. 1991;46:488-92.

8. Clough JB, Hutchinson SA, Williams JD, Holgate ST. Airway responses to exercise and methacholine in children with respiratory symptoms. Arch Dis Child. 1991;66:579-83.

9. McFadden ER Jr, Gilbert IA. Exercise-induced asthma. N Engl J Med. 1994;330:1362-7.

10. Ribeiro M, Silva RC, Pereira CA. Diagnóstico de asma: comparação entre o teste de broncoprovocação e variabilidade do pico de fluxo expiratório. J Pneumol. 1995;21:217-24.

11. Louis R, Lau LC, Bron AO, Roldaan AC, Radermecker M, Djukanovic $R$. The relationship between airways inflammation and asthma severity. Am J Respir Crit Care Med. 2000;161:9-16.

12. Foresi A, Mattoli S, Corbo GM, Polidori G, Ciappi G. Comparison of bronchial responses to ultrasonically nebulized distilled water, exercise, and methacholine in asthma. Chest. 1986;90:822-6.

13. Dawson B, Trapp RG. Research questions about two separate or independent groups. In: Dawson B, editor. Basic and Clinical Biostatistics. New York: Lange Medical Books; 2001. p. 132-60.

14. National Institutes of Health (NIH). Expert Panel Report 2: Guidelines for the Diagnosis and Management of Asthma. Bethesda, MD, USA, 1997. Publication no 97-4051-A, 50p.

15. American Thoracic Society. Standardization of Spirometry 1994. Am J Respir Crit Care Med. 1995;152:1107-36.

16. Polgar C, Promadhat V. Pulmonary function testing in children: techniques and standards. Philadelphia: WB Saunders Co.; 1991.

17. Godfrey S, Springer C, Bar-Yishay E, Avital A. Cut-off points defining normal and asthmatic bronchial reactivity to exercise and inhalation challenges in children and young adults. Eur Respir J. 1999;14:659-68.

18. Koh YI, Choi IS. Seasonal difference in the occurrence of exercise-induced bronchospasm in asthmatics: dependence on humidity. Respiration. 2002;69:38-45.

19. Astrand PO, Rodahl K. Circulação. In: Astrand PO, Rodahl K. Tratado de Fisiologia do Exercício. Trad. de Edmundo Vieites Novaes. $2^{\mathrm{a}}$ ed. Rio de Janeiro: Interamericana; 1980. p. 127-87.

20. King GG, Moore BJ, Seow CY, Pare PD. Airway narrowing associated with inhibition of deep inspiration during methacholine inhalation in asthmatics. Am J Respir Crit Care Med. 2001; 164:216-8.

21. West JV, Robertson CF, Roberts R, Olinsky A. Evaluation of bronchial responsiveness to exercise in children as an objective measure of asthma in epidemiological surveys. Thorax. 1996;51:590-5.

22. Haby MM, Anderson SD, Peat JK, Mellis CM, Toelle BG, Woolcock AJ. An exercise challenge protocol for epidemiological studies of asthma in children: comparison with Godfrey S, Springer C, BarYishay E, Avital A. Cut-off points defining normal and asthmatic bronchial reactivity to exercise and inhalation challenges in children and young adults. Eur Respir J. 1999;14:659-68.

23. Henriksen AH, Tveit KH, Holmen TL, Sue-Chu M, Bjermer L. A study of the association between exercise-induced wheeze and exercise versus methacholine-induced bronchoconstriction in adolescents. Pediatr Allergy Immunol. 2002;13:203-8.

24. Otani K, Kanazawa H, Fujiwara H, Hirata K, Fujimoto S, Yoshikawa J. Determinants of the severity of exercise-induced bronchoconstriction in patients with asthma. J Asthma 2004; 41:271-8.

25. Bundgaard A, Ingemann-Hansen $T$, Schmidt $A$, HalkjaerKristensen J. Exercise-induced asthma after walking, running and cycling. Scand J Clin Lab Invest. 1982;42:15-8.

26. Kallings LV, Emtner M, Backlund L. Exercise-induced bronchoconstriction in adults with asthma - comparison between running and cycling and between cycling at different air conditions. Ups J Med Sci. 1999;104:191-8.

27. Bar-Yishay E, Gur I, Inbar O, Neuman I, Dlin RA, Godfrey S. Differences between swimming and running as stimuli for exercise-induced asthma. Eur J Appl Physiol Occup Physiol. $1982 ; 48: 387-97$. 
28. McConnell $R$, Berhane $K$, Gilliland $F$, London $S$, Islam $T$, Gauderman WJ, et al. Asthma in exercising children exposed to ozone: a cohort study. Lancet. 2002;359:386-91.

29. Miller GJ, Davies BH, Cole TJ, Seaton A. Comparison of the bronchial response to running and cycling in asthma using an improved definition of the response to work. Thorax. 1975;30:306-11.

30. Koyal SN, Whipp BJ, Huntsman D, Bray GA, Wasserman K. Ventilatory responses to the metabolic acidosis of treadmill and cycle ergometry. J Appl Physiol. 1976;40:864-7.

31. Hermansen L, Ekblom B, Saltin B. Cardiac output during submaximal and maximal treadmill and bicycle exercise. J Appl Physiol. 1970;29:82-6.

32. Pannier JL, Vrijens J, VanCauter C. Cardiorespiratory responses to treadmill running and bicycle exercise in runners. Eur J Appl Physiol. 1980;43:243-51.
33. Gavin TP, Stager JM. The effect of exercise modality on exerciseinduced hypoxemia. Respir Physiol. 1999;115:317-23.

Corresponding author:

Ana Clara Toschi Gianotti de Souza

Rua Ibaragui Nissui, 138

CEP 04116-200 - São Paulo, SP

Brazil

Phone: +55 (11) 5571.5278

Fax: +55 (11) 287.0860

E-mail: anaclara@ajato.com.br 